\title{
Presence of mcr-1-positive Enterobacteriaceae in retail chicken meat but not in humans in the Netherlands
} since 2009

MF Kluytmans-van den Bergh ${ }^{12}$, P Huizinga ${ }^{3}$, MJ Bonten ${ }^{14}$, M Bos ${ }^{5}$, K De Bruyne ${ }^{6}$, AW Friedrich ${ }^{7}$, JW Rossen ${ }^{7}$, PH Savelkoul

89 , JA Kluytmans ${ }^{13}$

1. Julius Centre for Health Sciences and Primary Care, University Medical Center Utrecht, Utrecht, The Netherlands

2. Amphia Academy Infectious Disease Foundation, Amphia Hospital, Breda, The Netherlands

3. Laboratory for Microbiology and Infection Control, Amphia Hospital, Breda, The Netherlands

4. Department of Medical Microbiology, University Medical Center Utrecht, Utrecht, The Netherlands

5. Microbiome Ltd, Amsterdam, The Netherlands

6. Applied Maths NV, Sint-Martens-Latem, Belgium

7. Department of Medical Microbiology, University of Groningen, University Medical Center Groningen, Groningen, The Netherlands

8. Department of Medical Microbiology, Maastricht University Medical Centre, Maastricht, The Netherlands

9. Department of Medical Microbiology and Infection Control, VU University Medical Center, Amsterdam, The Netherlands

Correspondence: Marjolein Kluytmans-van den Bergh (marjoleinkluytmans@gmail.com)

Citation style for this article:

Kluytmans-van den Bergh M, Huizinga P, Bonten M, Bos M, De Bruyne K, Friedrich A, Rossen J, Savelkoul P, Kluytmans J. Presence of mcr-1-positive

Enterobacteriaceae in retail chicken meat but not in humans in the Netherlands since 2009. Euro Surveill. 2016;21(9):pii=30149. DOI: http://dx.doi.

org/10.2807/1560-7917.ES.2016.21.9.30149

Article submitted on 23 December 2015 / accepted on 01 February 2016 / published on 03 March 2016

Recently, the plasmid-mediated colistin resistance gene $m c r-1$ was found in Enterobacteriaceae from humans, pigs and retail meat in China. Several reports have documented global presence of the gene in Enterobacteriaceae from humans, food animals and food since. We screened several well-characterised strain collections of Enterobacteriaceae, obtained from retail chicken meat and hospitalised patients in the Netherlands between 2009 and 2015, for presence of colistin resistance and the $\mathrm{mcr}^{-1}$ gene. A total of 2,471 Enterobacteriaceae isolates, from surveys in retail chicken meat (196 isolates), prevalence surveys in hospitalised patients $(1,247$ isolates), clinical cultures (813 isolates) and outbreaks in healthcare settings (215 isolates), were analysed. The $m c r-1$ gene was identified in three $(1.5 \%)$ of 196 extended-spectrum beta-lactamase (ESBL)-producing Escherichia coli isolates from retail chicken meat samples in 2009 and 2014. Two isolates were obtained from the same batch of meat samples, most likely representing contamination from a common source. No mcr-1-positive isolates were identified among 2,275 human isolates tested. All mcr-1-positive isolates were colistin-resistant (minimum inhibitory concentration $(M I C)>2 \mathrm{mg} / \mathrm{L}$ ). Our findings indicate that $m c r-1$-based colistin-resistance currently poses no threat to healthcare in the Netherlands. They indicate however that continued monitoring of colistin resistance and its underlying mechanisms in humans, livestock and food is needed.

\section{Introduction}

The worldwide emergence of extended-spectrum betalactamases (ESBL) and carbapenemases has limited the available treatment options for infections with Gram-negative bacteria [1]. Colistin is considered to be an antibiotic of last resort for the treatment of infections with carbapenem-resistant bacteria, and its use in humans is increasing [1].

In November 2015, the presence of a plasmid-mediated colistin-resistance gene, $\mathrm{mcr}-1$, in Enterobacteriaceae from food animals, food and patients in China was reported [2]. The $m c r-1$ gene was detected in $21 \%$ of Escherichia coli isolates cultured from pigs at slaughter and in $15 \%$ of $E$. coli isolates cultured from retail meat between 2011 and 2014. In addition, the $\mathrm{mcr}-1$ gene was present in $1.4 \%$ of $E$. coli isolates and $0.7 \%$ of Klebsiella pneumoniae isolates from clinical cultures from patients in two Chinese hospitals in 2014. Directly following this publication, the $m c r-1$ gene was reported to be present in $0.2 \%$ of ESBL- and AmpC-producing $E$. coli isolates from human bloodstream infections, and in $2 \%$ of $E$. coli isolates cultured from imported chicken meat in Denmark since 2012 [3].Hereafter, several reports have documented the global presence of the $\mathrm{mcr}^{-1}$ gene in Enterobacteriaceae cultured from humans, food animals and food [4-13].

Traditionally, colistin resistance was thought to be mediated by chromosomal mutations only, and to spread exclusively via clonal transmission of resistant isolates [14]. The emergence of plasmid-mediated 


\section{TABLE 1}

Enterobacteriaceae isolates from retail chicken meat, rectal samples, clinical cultures and outbreaks by year of culture, type of isolate, and colistin-resistance, analysed by whole genome sequencing for the presence of the mcr-1 gene, the Netherlands, 2009-2015 ( $\mathrm{n}=2,471)$

\begin{tabular}{|c|c|c|c|c|c|}
\hline Isolate origin & Year & Type of isolate & $\begin{array}{l}\text { Number } \\
\text { of } \\
\text { isolates }\end{array}$ & $\begin{array}{c}\text { Number of } \\
\text { colistin-resistant } \\
\text { isolates }\end{array}$ & $\begin{array}{c}\text { Number of } \\
m c r-1 \text {-positive } \\
\text { isolates }\end{array}$ \\
\hline \multicolumn{6}{|l|}{ Retail chicken meat $(n=196)$} \\
\hline \multirow{2}{*}{ Prevalence survey $(n=74)$} & \multirow{2}{*}{2009} & ESBL-producing Escherichia coli & 68 & $\mathrm{NA}^{\mathrm{a}}$ & 1 \\
\hline & & ESBL-producing Klebsiella pneumoniae & 6 & NA & o \\
\hline \multirow{2}{*}{ Prevalence survey $(n=122)$} & \multirow{2}{*}{2014} & ESBL-producing E. coli & 119 & 2 & 2 \\
\hline & & ESBL-producing $K$. pneumoniae & 3 & o & o \\
\hline \multicolumn{6}{|c|}{ Hospitalised patients, rectal samples $(n=1,247)$} \\
\hline \multirow{2}{*}{$\begin{array}{l}\text { Prevalence survey, } 4 \text { hospitals } \\
(n=50)\end{array}$} & \multirow{2}{*}{2009} & ESBL-producing E. coli & 39 & NA & 0 \\
\hline & & ESBL-producing $K$. pneumoniae & 11 & NA & 0 \\
\hline \multirow{3}{*}{$\begin{array}{l}\text { Prevalence surveys, } 1 \text { hospital } \\
(n=63)\end{array}$} & \multirow{3}{*}{$2013-2014$} & ESBL-producing $E$. coli & 54 & 0 & 0 \\
\hline & & ESBL-producing $K$. pneumoniae & 8 & o & 0 \\
\hline & & ESBL-producing $K$. oxytoca & 1 & o & o \\
\hline \multirow{7}{*}{$\begin{array}{l}\text { Prevalence surveys, } 14 \text { hospitals } \\
(n=1,134)\end{array}$} & \multirow{7}{*}{$2011-2014$} & ESBL-producing $E$. coli & 821 & 2 & o \\
\hline & & ESBL-producing $K$. pneumoniae & 172 & 3 & o \\
\hline & & ESBL-producing K. oxytoca & 13 & o & o \\
\hline & & ESBLproducing Enterobacter cloacae & 77 & 2 & o \\
\hline & & ESBL-producing Citrobacter spp. & 38 & 1 & 0 \\
\hline & & ESBL-producing Morganella morganii & 6 & $6^{\mathrm{b}}$ & 0 \\
\hline & & Other ESBLproducing Enterobacteriaceae & 7 & 0 & o \\
\hline \multicolumn{6}{|c|}{ Hospitalised patients, clinical cultures $(n=813)$} \\
\hline \multirow{3}{*}{ Blood cultures, 4 hospitals $(n=25)$} & \multirow{3}{*}{2009} & ESBL-producing E. coli & 16 & NA & o \\
\hline & & ESBL-producing K. pneumoniae & 7 & NA & 0 \\
\hline & & ESBL-producing $K$. oxytoca & 2 & NA & 0 \\
\hline \multirow{3}{*}{ Blood cultures, 4 hospitals $(n=77)$} & \multirow{3}{*}{$2013-2014$} & ESBL-producing E. coli & $67^{c}$ & 0 & o \\
\hline & & ESBL-producing $K$. pneumoniae & $8^{c}$ & 0 & o \\
\hline & & ESBL-producing $K$. oxytoca & 2 & 0 & 0 \\
\hline \multirow{9}{*}{$\begin{array}{l}\text { Clinical cultures, } 14 \text { hospitals } \\
(n=711)\end{array}$} & \multirow{9}{*}{$2011-2014$} & ESBL-producing $E$. coli & 546 & 4 & 0 \\
\hline & & ESBL-producing $K$. pneumoniae & 101 & 2 & 0 \\
\hline & & ESBL-producing $K$. oxytoca & 5 & 0 & 0 \\
\hline & & ESBL-producing $E$. cloacae & 46 & 3 & 0 \\
\hline & & ESBL-producing Citrobacter spp. & 4 & 0 & o \\
\hline & & ESBL-producing M. morganii & 3 & $3^{b}$ & 0 \\
\hline & & ESBL-producing Proteus mirabilis & 2 & $2^{\mathrm{b}}$ & 0 \\
\hline & & ESBL-producing $P$. vulgaris group & 1 & $1^{b}$ & 0 \\
\hline & & Other ESBL-producing Enterobacteriaceae & 3 & 0 & o \\
\hline \multicolumn{6}{|c|}{ Outbreaks in healthcare settings $(n=215)$} \\
\hline $\begin{array}{l}\text { Several wards, including } \\
\text { rehabilitation centre }(n=29)^{d}\end{array}$ & $2012-2015$ & СТX-M-15 producing $K$. pneumoniae & 29 & 0 & o \\
\hline Surgical ward $(n=14)$ & 2014 & E. cloacae & 14 & 0 & 0 \\
\hline Intensive care unit $(\mathrm{n}=86)$ & $2009-2014$ & Colistin-resistant E. cloacae & 86 & 86 & 0 \\
\hline Nursing home $(n=10)$ & 2012 & Colistin-resistant KPC-producing K. pneumoniae & 10 & 10 & o \\
\hline ERCP related procedures $(n=50)$ & $2014-2015$ & Colistin-resistant $K$. pneumoniae & 50 & 43 & 0 \\
\hline $\begin{array}{l}\text { Neonatal intensive care unit } \\
(\mathrm{n}=26)^{\mathrm{d}}\end{array}$ & $2014-2015$ & Colistin-resistant Serratia marcescens & 26 & $26^{\mathrm{b}}$ & 0 \\
\hline
\end{tabular}

ERCP: endoscopic-retrograde cholangio-pancreaticography; ESBL: extended-spectrum beta-lactamase; KPC: Klebsiella pneumoniae carbapenemase; NA: not available.

a The $m c r$-1-positive isolate was tested colistin-resistant with Etest.

${ }^{b}$ Intrinsic resistance.

${ }^{c}$ Two $E$. coli isolates and one $K$. pneumoniae isolate were not available for whole genome sequencing.

${ }^{d}$ Outbreak and subsequent surveillance.

Colistin resistance was defined as a colistin minimum inhibitory concentration (MIC) $>2 \mathrm{mg} / \mathrm{L}$, according to the European Committee on Antimicrobial Susceptibility Testing (EUCAST) clinical breakpoints [26] 
TABLE 2

Characteristics of the mcr-1-positive Escherichia coli isolates from retail chicken meat, the Netherlands, 2009-2015

\begin{tabular}{|c|c|c|c|c|c|c|c|}
\hline Isolate & Origin & $\begin{array}{l}\text { Date of } \\
\text { purchase }\end{array}$ & Supermarket & MLST & Serotype & Resistance genes & $\begin{array}{l}\text { Plasmid } \\
\text { replicons }\end{array}$ \\
\hline 213 & $\begin{array}{c}\text { Chicken } \\
\text { meat }\end{array}$ & $\begin{array}{l}14 \text { October } \\
2009\end{array}$ & A & ST2079 & 08:H19 & 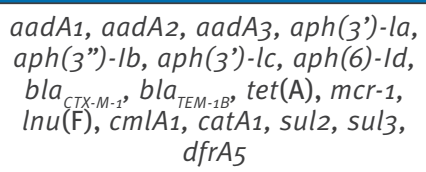 & $\begin{array}{l}\text { FIB, FII, HI2, } \\
\text { HI2A, I1, I2, } \\
\text { P, po111 }\end{array}$ \\
\hline $14 \mathrm{Mo09386}^{\mathrm{a}}$ & $\begin{array}{c}\text { Chicken } \\
\text { meat }\end{array}$ & $\begin{array}{c}29 \text { January } \\
2014\end{array}$ & B & $\mathrm{ST} 117$ & O159: 4 & aadA1, bla ${ }_{S H V-12}, m c r-1$, sul1, sul3 & FIB, FII \\
\hline $14 \mathrm{Mo09387^{ \textrm {a } }}$ & $\begin{array}{c}\text { Chicken } \\
\text { meat }\end{array}$ & $\begin{array}{l}29 \text { January } \\
2014\end{array}$ & B & ST117 & O159: 44 & aadA1, bla ${ }_{S H V-12}, m c r-1$, sul1, sul3 & $\mathrm{FIB}, \mathrm{FII}$ \\
\hline
\end{tabular}

MLST: multilocus sequence typing.

a Isolate 14 Mo09386 and 14M009387 were cultured from different meat samples with the same lot number.

colistin resistance enables the much more efficient horizontal transfer of colistin resistance genes to other bacteria, making mcr-1 a potential threat to public health. The aim of this study was to screen several welldocumented strain collections of Enterobacteriaceae, obtained from retail chicken meat and hospitalised patients in the Netherlands since 2009 , for the presence of colistin resistance and the $m c r-1$ gene.

\section{Methods}

\section{Strain collections}

A total number of 2,471 Enterobacteriaceae isolates were analysed for the presence of colistin resistance and the $m c r-1$ gene. Isolates originated from prevalence surveys in retail chicken meat (196 isolates), prevalence surveys in hospitalised patients (1,247 isolates), clinical cultures (813 isolates) and several outbreaks in healthcare settings (215 isolates), all collected in the Netherlands between 2009 and 2015.

\section{Retail chicken meat}

Two ESBL-producing Enterobacteriaceae (ESBL-E) prevalence surveys in Dutch retail chicken meat were performed in 2009 and in $2014[15,16]$. A total number of 196 ESBL-E isolates were obtained, 74 isolates from 71 ESBL-E-positive meat samples in 2009 (89 samples cultured), and 122 isolates from 86 ESBL-E-positive meat samples in 2014 (101 meat samples cultured).

\section{Hospitalised patients, rectal samples}

The retail chicken meat surveys in 2009 and 2014 were accompanied by hospital-wide prevalence surveys in patients who were admitted to four hospitals in the region where the chicken meat was bought $[15,16]$. In 2009 , ESBL-E rectal carriage was detected in $45(5.1 \%)$ of 876 patients, who carried $50 \mathrm{ESBL}-\mathrm{E}$ isolates. Two repeated prevalence surveys in one of the four hospitals in 2013 and 2014, yielded 63 ESBL-E isolates obtained from 63 (5.9\%) ESBL-E carriers among 1,065 patients cultured [17].
A multi-centre cluster-randomised study comparing contact isolation strategies for known ESBL-E carriers was performed in 14 Dutch hospitals between 2011 and 2014 (SoM study) [18]. All consecutive adult patients with a routine clinical culture with ESBL-E were placed on contact precautions and enrolled in the study (=index patient). Ward-based ESBL-E prevalence surveys were performed one week after enrolment of the index patient. Perianal swabs were obtained from 10,691 patients and identified 992 (9.3\%) ESBL-E carriers, from whom 1,134 ESBL-E isolates were cultured.

Hospitalised patients, clinical cultures

In 2009, 2013 and 2014, all consecutive ESBL-E isolates from blood cultures were prospectively collected in the four hospitals that participated in the ESBL-E rectal carriage prevalence surveys $[15,16]$. A total number of 102 ESBL-isolates from blood cultures were obtained, 25 isolates from 23 patients with an ESBL-E-positive blood culture in 2009, and 77 isolates from 76 patients in 2013 and 2014. Three isolates that were collected in 2014 were not available for whole genome sequencing. In the SoM study, a total number of 711 clinical ESBL-E isolates were obtained from 654 ESBL-E-positive patients.

\section{Outbreaks in healthcare settings}

Since 2009, several outbreaks with antimicrobialresistant bacteria in Dutch hospitals and nursing homes have been documented. Six outbreaks, comprising 215 isolates, for which whole genome sequence data were available, were included in this analysis: (i) an outbreak of CTX-M-15-producing $K$. pneumoniae in several wards of a hospital and an associated rehabilitation centre in 2012-2015 (29 isolates) [19]; (ii) an outbreak of Enterobacter cloacae in a surgical ward in 2014 (14 isolates); (iii) an outbreak of colistin-resistant E. cloacae in an intensive care unit between 2009 and 2014 (86 isolates); (iv) an outbreak of colistin-resistant KPCproducing $K$. pneumoniae in a nursing home in 2012 (10 isolates) [20]; (v) an outbreak of colistin-resistant K. pneumoniae in patients after endoscopic retrograde cholangio-pancreaticography (ERCP) procedures in 
TABLE 3

Antimicrobial susceptibility of mcr-1-positive Escherichia coli isolates from retail chicken meat, the Netherlands, 2009-2015

\begin{tabular}{|c|c|c|c|c|c|c|}
\hline \multirow{3}{*}{ Antimicrobial agent } & \multicolumn{6}{|c|}{ Isolate } \\
\hline & \multicolumn{2}{|c|}{213} & \multicolumn{2}{|c|}{$14 M 009386$} & \multicolumn{2}{|c|}{$14 M 009387$} \\
\hline & MIC (mg/L) & $S / I / R$ & MIC (mg/L) & $S / I / R$ & MIC (mg/L) & $S / 1 / R^{a}$ \\
\hline \multicolumn{7}{|l|}{ Polymyxins } \\
\hline Colistin & $3^{b}$ & $R$ & $\geq 16$ & $R$ & $\geq 16$ & $R$ \\
\hline \multicolumn{7}{|l|}{ Penicillins } \\
\hline Ampicillin & $\geq 32$ & $R$ & $\geq 32$ & $R$ & $\geq 32$ & $R$ \\
\hline Amoxicillin/clavulanic acid & 8 & $\mathrm{~S}$ & $\leq 2$ & $\mathrm{~S}$ & 4 & $\mathrm{~S}$ \\
\hline Piperacillin/tazobactam & $\leq 4$ & $\mathrm{~S}$ & $\leq 4$ & $\mathrm{~S}$ & $\leq 4$ & $\mathrm{~S}$ \\
\hline \multicolumn{7}{|l|}{ Cephalosporins } \\
\hline Cefuroxime & $\geq 64$ & $R$ & 16 & $R$ & 16 & $R$ \\
\hline Cefotaxime & 8 & $R$ & 4 & $R$ & 4 & $R$ \\
\hline Ceftazidime & $\leq 1$ & $\mathrm{~S}$ & 16 & $R$ & 16 & $R$ \\
\hline Cefepime & 2 & 1 & $\leq 1$ & $\mathrm{~S}$ & $\leq 1$ & $\mathrm{~S}$ \\
\hline Cefoxitin & $\leq 4$ & $\mathrm{~S}^{\mathrm{c}}$ & $\leq 4$ & $\mathrm{~S}^{\mathrm{c}}$ & $\leq 4$ & $\mathrm{~S}^{\mathrm{c}}$ \\
\hline \multicolumn{7}{|l|}{ Carbapenems } \\
\hline Meropenem & $\leq 0.25$ & $\mathrm{~S}$ & $\leq 0.25$ & $\mathrm{~S}$ & $\leq 0.25$ & $\mathrm{~S}$ \\
\hline Imipenem & $\leq 0.25$ & $\mathrm{~S}$ & $\leq 0.25$ & $\mathrm{~S}$ & $\leq 0.25$ & $\mathrm{~S}$ \\
\hline \multicolumn{7}{|l|}{ Aminoglycosides } \\
\hline Gentamicin & $\leq 1.0$ & $\mathrm{~S}$ & $\leq 1$ & $\mathrm{~S}$ & $\leq 1$ & $\mathrm{~S}$ \\
\hline Tobramycin & $\leq 1.0$ & $\mathrm{~S}$ & $\leq 1$ & $\mathrm{~s}$ & $\leq 1$ & $\mathrm{~S}$ \\
\hline \multicolumn{7}{|l|}{ Fluoroquinolones } \\
\hline Ciprofloxacin & 0.5 & $\mathrm{~S}$ & $\leq 0.25$ & $\mathrm{~S}$ & $\leq 0.25$ & $\mathrm{~S}$ \\
\hline Norfloxacin & 2 & $R$ & $\leq 0.5$ & $\mathrm{~S}$ & $\leq 0.5$ & $\mathrm{~S}$ \\
\hline \multicolumn{7}{|l|}{ Folate pathway inhibitors } \\
\hline Trimethoprim/sulfamethoxazol & $\geq 16 / 304$ & $R$ & $\leq 1 / 19$ & $\mathrm{~S}$ & $\leq 1 / 19$ & $\mathrm{~S}$ \\
\hline
\end{tabular}

I: intermediate; MIC: minimum inhibitory concentration; R: resistant; S: susceptible.

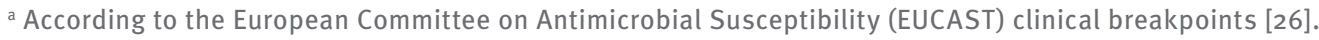

${ }^{b}$ Etest: $\mathrm{MIC}=3 \mathrm{mg} / \mathrm{L}$; Vitek2: $\mathrm{MIC}=2 \mathrm{mg} / \mathrm{L}$.

' No clinical breakpoint available; S refers to the screening breakpoint for AmpC Enterobacteriaceae.

2014-2015 (50 isolates); and (vi) an outbreak of (intrinsic) colistin-resistant Serratia marcescens in a neonatal intensive care unit in 2014-2015 (26 isolates).

\section{Whole genome sequencing and analysis of sequence data}

Whole genome sequencing (WGS) was performed, on either a MiSeq, HiSeq 2500 or NextSeq sequencer (Illumina). De novo assembly was performed using CLC genomics Workbench 7.0.4 (Qiagen) or the open source SPAdes 3.5.0 software (http://bioinf.spbau.ru/spades) [21]. Sequence data were screened for the presence of the $m r c-1$ gene by running the assembled sequences against a task template containing the $\mathrm{mcr}$-1 gene sequence in Ridom SeqSphere + version 3.0.1 (Ridom, Germany) or by uploading the assembled sequences to the open access bioinformatic webtool ResFinder (updated version 2.1, including the mcr-1 sequence) of the Center for Genomic Epidemiology (http://www. genomicepidemiology.org/) [22]. For isolates from two outbreaks (colistin-resistant E. cloacae and ERCPrelated colistin-resistant $K$. pneumonia), the thresholds for sequence identity and coverage length were set to
$98 \%$ and $60 \%$, respectively, while for all other isolates both thresholds were set to $80 \%$. The sequence data of the mcr-1-positive isolates were further analysed by using a genotyping plugin that allowed serotyping of the isolates and detection of acquired antibiotic resistance genes and plasmids with a $80 \%$ threshold for both sequence identity and coverage length (BioNumerics v7.6 beta software, Applied Maths). Reference data for acquired antimicrobial resistance genes and plasmid replicons were retrieved from the ResFinder and PlasmidFinder databases (version 9 November 2015) of the Center for Genomic Epidemiology (http://www. genomicepidemiology.org/) [22,23]. Whole genome multilocus sequence typing (wgMLST) analysis was performed using a pan-genome MLST scheme comprising 9,347 genes, based on 19 well-annotated reference genomes of $E$. coli and Shigella spp. (BioNumerics v7.6 beta, Applied Maths). Additionally, single nucleotide polymorphism (SNP) calling was performed by mapping the paired-end reads of isolate 14 Moo9387 and isolate 213 to the de novo assembled genome of isolate 14Moo9386, using Bowtie 2.5.5 [24] and SAMtools [25]. Resulting Binary Alignment Maps (BAM) files were 
TABLE 4

Whole genome multilocus sequence typing analysis and whole genome single nucleotide polymorphism analysis of $m c r-1$-positive isolates from retail chicken meat, the Netherlands, 2009-2015

\begin{tabular}{|l|c|c|c|c|}
\hline \multirow{2}{*}{ Isolate } & \multicolumn{3}{|c|}{ wgMLST } & wgSNP \\
\cline { 2 - 5 } & Loci shared & \multicolumn{2}{c|}{$\begin{array}{c}\text { Different alleles } \\
\text { within shared loci }\end{array}$} & $\begin{array}{c}\text { SNP } \\
\text { positions }\end{array}$ \\
\cline { 2 - 5 } & $\mathrm{n}$ & $\mathrm{n}$ & $\%$ & $\mathrm{n}$ \\
\hline 14 Mo09387 & 4,243 & 3 & $0.07 \%$ & 8 \\
\hline 213 & 3,791 & 3,606 & $95.1 \%$ & 100,215 \\
\hline
\end{tabular}

MLST: multilocus sequence typing; SNP: single nucleotide polymorphism; wg: whole genome.

a Isolate 14 Mo009386 was used as reference.

used to perform whole genome SNP (wgSNP) analysis (BioNumerics v7.6 beta, Applied Maths).

Antimicrobial susceptibility testing

Isolates for which antimicrobial susceptibility data were available were screened for the presence of colistin resistance. Susceptibility testing of the three $\mathrm{mcr}$ 1-positive $E$. coli isolates was performed using Vitek2 (bioMérieux, France) and Etest (bioMérieux, France). The breakpoint tables of the European Committee on Antimicrobial Susceptibility Testing (EUCAST) were used for the interpretation of minimum inhibitory concentrations (MICs) [26]. Isolates with a colistin MIC > 2 $\mathrm{mg} / \mathrm{L}$ were considered colistin-resistant.

\section{Results}

An overview of the 2,471 Enterobacteriaceae isolates from retail chicken meat, rectal samples, clinical cultures and outbreaks is presented in Table 1 . Colistin resistance was found in two (1.6\%) of 122 chicken meat-derived ESBL-E isolates, in 14 (1.1\%) of 1,247 isolates from ESBL-E rectal carriers, and in 15 (1.8\%) of 813 ESBL-E isolates from clinical cultures. The $\mathrm{mcr}-1$ gene was detected in three $(1.5 \%)$ of 196 chicken meatderived $\mathrm{ESBL}$-producing $E$. coli isolates, one cultured in 2009 and two in 2014. For all three isolates, the $\mathrm{mcr}-1$ sequence showed $100 \%$ similarity to the gene reported in China [2]. None of the 2,275 human isolates harboured the $m c r-1$ gene.

Table 2 shows the general and molecular characteristics of the three $m c r-1$-positive $E$. coli isolates. The isolate that was cultured in 2009 had sequence type ST2079, was CTX-M-1-positive and harboured 17 acquired resistance genes. Both isolates from 2014 had sequence type ST117, were SHV-12-positive and harboured five acquired resistance genes. Although these two isolates were cultured from different meat samples of non-Dutch origin, the meat samples had the same lot number and were bought in the same supermarket on the same day. Plasmid replicons were identified in all three isolates, eight in the isolate from 2009 and two in both isolates from 2014. However, none of the plasmid replicons could be linked to the $m c r-1$ gene.
Antimicrobial susceptibilities for the three mcr-1-positive $E$. coli isolates are shown in Table 3. All three isolates were colistin-resistant (MIC $>2 \mathrm{mg} / \mathrm{L})$. The isolate from 2009 tested colistin-susceptible by Vitek2 $(\mathrm{MIC}=2 \mathrm{mg} / \mathrm{L})$, but resistant by Etest $(\mathrm{MIC}=3 \mathrm{mg} / \mathrm{L})$. wgMLST analysis showed that the two isolates from 2014 differed by only three (0.07\%) of 4,243 shared loci, whereas the isolate from 2009 differed by 3,606 (95.1\%) of 3,791 shared loci (Table 4). The two isolates from 2014 differed by only eight SNPs in wgSNP analysis.

\section{Discussion}

In our study, covering the period 2009 to 2015, we detected the recently described plasmid-mediated colistin resistance gene, $m c r-1$, in three ESBL-producing $E$. coli isolates from retail chicken meat samples obtained from Dutch supermarkets in 2009 and 2014. All three mcr-1-positive isolates were colistin-resistant, and two of them were genetically closely related. No mcr-1-positive isolates were detected in a large collection of Enterobacteriaceae isolates of human origin that were collected during the same time period and included isolates of four outbreaks with colistin-resistant Enterobacteriaceae.

In addition to the recent reports on the global occurrence of the $m c r-1$ gene in Enterobacteriaceae cultured from humans, food animals and food [2-13], our findings confirm the presence of the $m c r-1$ gene in the European setting already since 2009 .

The observed $1.5 \%$ prevalence of $\mathrm{mcr}$-1-positive isolates is comparable with the reported $2 \%(5 / 255)$ prevalence in imported chicken meat in Denmark, and is lower than the $15 \%(78 / 523)$ prevalence in retail meat in China [2,3]. This lower prevalence may be related to the relatively low rates of polymyxin use in livestock in Europe. In 2014, polymyxins constituted only $0.4 \%$ (0.34 defined daily dose animal (DDDA)/animal year) of all antibiotics used in broilers in the Netherlands, with a decreasing trend over the last few years [27].

It is noteworthy that the observed $1.5 \%$ prevalence of mcr-1-positive isolates in ESBL-E isolates from retail chicken meat in this study is similar to the $1.5 \%$ phenotypic colistin resistance that was found in $E$. coli isolates cultured from Dutch retail chicken meat in 2014 [27]. Unfortunately, no data are currently available on the resistance mechanisms involved in this phenotypic colistin resistance.

The genetic identity between the two $\mathrm{mcr}$-1-positive isolates that were obtained from the same batch of meat samples most likely represents batch contamination from a common source.

The $m c r$-1-positive isolates in this study belong to different sequence types as compared with those that were found to be related to the $m c r-1$ gene in the Chinese and Danish study [2,3]. E. coli ST2097 is uncommon in 
humans, but has been reported once before in a study on ESBL-producing bacteria in flies from broiler farms in the Netherlands [28]. E. coli ST117, on the other hand, is common in both poultry and humans $[16,29]$. The detection of the $m c r-1$ gene in isolates that belong to different sequence types illustrates the potential for horizontal transfer of this resistance gene.

Although all chicken meat samples were bought in Dutch supermarkets, the labelling of the samples did not provide any clue with respect to the country where animals were raised. Available data on the origin of the chicken meat were limited to the producing country for the samples from 2014 (non-Dutch, European), for the 2009 isolate this information was not available. A nonEuropean origin of the mcr-1-positive meat samples can, therefore, neither be confirmed, nor excluded.

The absence of the $m c r-1$ gene in human isolates of various origins is in accordance with observations in previous studies that the presence of the $\mathrm{mcr}-1$ gene in clinical isolates is still rare. In China, 1.4\% (13/902) of clinical $E$. coli isolates and $0.7 \%$ (3/420) of clinical $K$. pneumoniae isolates were $m c r-1$-positive, and in Denmark, only $0.2 \%(1 / 417)$ of ESBL- and AmpCproducing $E$. coli isolates from bloodstream infections $[2,3]$. This absence of the $m c r-1$ gene in current Dutch collections of human Enterobacteriaceae may in part be due to the low use of colistin and its analogues, the polymyxins, in humans in the Netherlands. In 2014, polymyxins constituted less than $0.1 \%$ (0.01 defined daily dose (DDD)/1,00o inhabitant-days) of all systemic antimicrobials used in primary care and ca $0.3 \%$ (0.2 DDD/10o patient-days) of systemic antimicrobials used in the hospital setting [30].

Short-read sequence data are not optimal for the assembly of plasmid sequences, which are known to contain multiple repetitive elements. This may explain why the analysis of our sequence data did not reveal a link between the $m c r-1$ gene and the plasmid replicons identified.

Although the prevalence of mcr-1-positive isolates in meat samples was low, the presence of this colistin resistance gene in food represents a potential public health threat, as it is located on mobile genetic elements that have the potential to spread horizontally to other bacteria. With the increase in carbapenem resistance, the use of colistin is increasing and, herewith, the selective pressure for the spread of $\mathrm{mcr}-1$ genecontaining plasmids. As colistin has become one of the last resort antibiotic options to treat severe infections with Gram-negative bacteria, the continued monitoring of colistin resistance and its underlying resistance mechanisms is important, not only in humans, but also in food production animals and food. The emergence of plasmid-mediated colistin resistance underpins the recent proposal of veterinary experts to reconsider the use of colistin and its analogues in food production animals [31].
In conclusion, the plasmid-mediated colistin resistance gene $m c r-1$ was detected in three ESBL-producing $E$. coli isolates that had been cultured from retail chicken meat from Dutch supermarkets in 2009 and 2014. Two isolates were obtained from the same batch of meat samples, which most likely represents contamination from a common source. The mcr-1 gene was not present in a large collection of human isolates collected between 2009 and 2015 in the Netherlands. These findings indicate that $\mathrm{mcr}$-1-based colistin resistance currently poses no threat to healthcare in the Netherlands, but requires continued monitoring of colistin resistance and its underlying mechanisms in humans, livestock and food.

\section{Acknowledgements}

The SoM study was supported by The Netherlands Organisation for Health Research and Development (ZonMw) (project 205100010). Part of this study was funded by the Food \& Nutrition Delta Program 2013. We are grateful to the members of the SoM study group for their contribution to this study.

\section{Conflict of interest}

Katrien De Bruyne is an employee of Applied Maths, a company that develops and sells software for microbiological typing methods. All other authors have no competing interest to declare.

\section{Authors' contributions}

MK, MJMB, JR, PH collected the data, MK, MB, JR and KDB performed the molecular analysis, MK, PH, MJMB, MB, KDB, $J R, A F, P S$ and JK participated in drafting the manuscript, MK coordinated and edited the manuscript.

\section{References}

1. Doi Y, Paterson DL. Carbapenemase-producing Enterobacteriaceae.Semin Respir Crit Care Med. 2015;36(1):7484.DOI: $10.1055 / \mathrm{s}-0035-1544208$ PMID: 25643272

2. Liu YY, Wang Y, Walsh TR, Yi LX, Zhang R, Spencer J, et al. Emergence of plasmid-mediated colistin resistance mechanism MCR-1 in animals and human beings in China: a microbiological and molecular biological study. Lancet Infect Dis. 2016;16(2):161-8. DOI: 10.1016/S1473-3099(15)00424-7 PMID: 26603172

3. Hasman H, Hammerum AM, Hansen F, Hendriksen RS, Olesen $B$, Agers $\varnothing$, et al. Detection of mcr-1 encoding plasmidmediated colistin-resistant Escherichia coli isolates from human bloodstream infection and imported chicken meat, Denmark 2015. Euro Surveill. 2015;20(49):30085.DOI: 10.2807/1560-7917.ES.2015.20.49.30085 PMID: 26676364

4. COMBAT consortium, Arcilla MS, van Hattem JM, Matamoros S, Melles DC, Penders J, de Jong MD, et al. . Dissemination of the $\mathrm{mcr}-1$ colistin resistance gene.Lancet Infect Dis. 2016;16(2):147-9. DOI: 10.1016/S1473-3099(15)00541-1 PMID: 26711361

5. Olaitan AO, Chabou S, Okdah L, Morand S, Rolain JM. Dissemination of the mcr-1 colistin resistance gene.Lancet Infect Dis. 2016;16(2):147.DOI: 10.1016/S1473-3099(15)00540-X PMID: 26711360

6. Webb HE, Granier SA, Marault M, Millemann Y, den Bakker $\mathrm{HC}$, Nightingale KK, et al. Dissemination of the $\mathrm{mcr}-1$ colistin resistance gene. Lancet Infect Dis. 2015. DOI: 10.1016/ S1473-3099(15)00538-1

7. Public Health England (PHE). First detection of plasmidmediated colistin resistance (mcr-1 gene) in food and human 
isolates in England and Wales (Serial number 2015/090). London: PHE, 2015.

8. Falgenhauer L, Waezsada SE, Yao Y, Imirzalioglu C, Käsbohrer $A$, Roesler $U$, et al.; RESET consortium. Colistin resistance gene mcr-1 in extended-spectrum $\beta$-lactamase-producing and carbapenemase-producing Gram-negative bacteria in Germany. Lancet Infect Dis. 2016.

9. Malhotra-Kumar S, Xavier BB, Das AJ, Lammens C, Butaye P, Goossens H. Colistin resistance gene $\mathrm{mcr}-1$ harboured on a multidrug resistant plasmid. Lancet Infect Dis. 2016.

10. Malhotra-Kumar S, Xavier BB, Das AJ, Lammens C, Hoang HTT, Pham NT, et al. Colistin-resistant Escherichia coli harbouring mcr-1 isolated from food animals in Hanoi, Vietnam. Lancet Infect Dis. 2016.

11. Stoesser N, Mathers AJ, Moore CE, Day NPJ, Crook DW. Colistin resistance gene $\mathrm{mcr}-1$ and pHNSHP 45 plasmid in human isolates of Escherichia coli and Klebsiella pneumoniae. Lancet Infect Dis. 2016.

12. Suzuki S, Ohnishi M, Kawanishi M, Akiba M, Kuroda M. Investigation of a plasmid genome database for colistinresistance gene mcr-1. Lancet Infect Dis. 2016.

13. Haenni M, Poirel L, Kieffer N, Châtre $P$, Saras E, Métayer V, et al. Co-occurrence of extended spectrum $\beta$ lactamase and MCR1 encoding genes on plasmids. Lancet Infect Dis. 2016.

14. Giani T, Arena F, Vaggelli G, Conte V, Chiarelli A, Henrici De Angelis L, et al. Large nosocomial outbreak of colistinresistant, carbapenemase-producing Klebsiella pneumoniae traced to clonal expansion of an mgrB deletion mutant. J Clin Microbiol. 2015;53(10):3341-4.DOI: 10.1128/JCM.01017-15 PMID: 26202124

15. Kluytmans JAJW, Overdevest ITMA, Willemsen I, Kluytmans-van den Bergh MFQ, van der Zwaluw K, Heck M, et al. Extendedspectrum $\beta$-lactamase-producing Escherichia coli from retail chicken meat and humans: comparison of strains, plasmids, resistance genes, and virulence factors. Clin Infect Dis. 2013;56(4):478-87.DOI: 10.1093/cid/cis929 PMID: 23243181

16. Overdevest I, Willemsen I, Rijnsburger M, Eustace A, Xu L, Hawkey $P$, et al. Extended-spectrum $\beta$-lactamase genes of Escherichia coli in chicken meat and humans, The Netherlands. Emerg Infect Dis. 2011;17(7):1216-22.DOI: 10.3201/ eid1707.110209 PMID: 21762575

17. Willemsen I, Oome S, Verhulst C, Pettersson A, Verduin K, Kluytmans J. Trends in extended spectrum beta-lactamase (ESBL) producing Enterobacteriaceae and ESBL genes in a Dutch teaching hospital, measured in 5 yearly point prevalence surveys (2010-2014).PLoS One. 2015;10(11):e0141765.DOI: 10.1371/journal.pone.0141765 PMID: 26528549

18. Nederlands Trial Register. Trial ID NTR2799. Amsterdam: Nederlands Trial Register. [Accessed 25 Feb 2016]. Available from: http://www.trialregister.nl/trialreg/admin/rctview. asp?TC $=2799$

19. Zhou K, Lokate M, Deurenberg RH, Arends J, Lo-Ten Foe J, Grundmann H, et al. Characterization of a CTX-M-15 producing Klebsiella pneumoniae outbreak strain assigned to a novel sequence type (1427). Front Microbiol. 2015;6:1250.DOI: 10.3389/fmicb.2015.01250 PMID: 26617589

20. Weterings V, Zhou K, Rossen JW, van Stenis D, Thewessen E, Kluytmans J, et al. An outbreak of colistin-resistant Klebsiella pneumoniae carbapenemase-producing Klebsiella pneumoniae in the Netherlands (July to December 2013), with inter-institutional spread. Eur J Clin Microbiol Infect Dis. 2015;34(8):1647-55.DOI: 10.1007/S10096-015-2401-2 PMID: 26067658

21. Bankevich A, Nurk S, Antipov D, Gurevich AA, Dvorkin M, Kulikov AS, et al. SPAdes: a new genome assembly algorithm and its applications to single-cell sequencing. J Comput Biol. 2012;19(5):455-77.DOI: 10.1089/cmb.2012.0021 PMID: 22506599

22. Zankari E, Hasman H, Cosentino S, Vestergaard M, Rasmussen $\mathrm{S}$, Lund $\mathrm{O}$, et al. Identification of acquired antimicrobial resistance genes. J Antimicrob Chemother. 2012;67(11):2640-4. DOI: 10.1093/jac/dks261 PMID: 22782487

23. Carattoli A, Zankari E, García-Fernández A, Voldby Larsen M, Lund $\mathrm{O}$, Villa $\mathrm{L}$, et al. In silico detection and typing of plasmids using PlasmidFinder and plasmid multilocus sequence typing. Antimicrob Agents Chemother. 2014;58(7):3895-903.DOI: 10.1128/AAC.02412-14 PMID: 24777092

24. Langmead B, Salzberg SL. Fast gapped-read alignment with Bowtie 2.Nat Methods. 2012;9(4):357-9.DOI: 10.1038/ nmeth.1923 PMID: 22388286

25. 1000 Genome Project Data Processing Subgroup,Li H, Handsaker B, Wysoker A, Fennell T, Ruan J, Homer N, et al. . The Sequence Alignment/Map format and SAMtools. Bioinformatics. 2009;25(16):2078-9.DOI: 10.1093/ bioinformatics/btp352 PMID: 19505943
26. European Committee on Antimicrobial Susceptibility Testing (EUCAST). Breakpoint tables for interpretation of MICs and zone diameters. Version 5.0, 2015. Available from: http://www. eucast.org/clinical_breakpoints/

27. Central Veterinary Institute of Wageningen University and Research Centre. MARAN 2015. Monitoring of antimicrobial resistance and antibiotic usage in animals in The Netherlands in 2014. 2015. Available from: http://www.swab.nl/swab/cms3. nsf/uploads/4F5AoD8E6FoDD139C1257E6E0051833A/\$FILE/ NethmapMaran2015\%20_webversie.pdf

28. Blaak H, Hamidjaja RA, van Hoek AHAM, de Heer L, de Roda Husman AM, Schets FM. Detection of extended-spectrum betalactamase (ESBL)-producing Escherichia coli on flies at poultry farms.Appl Environ Microbiol. 2014;80(1):239-46.DOI: 10.1128/ AEM.02616-13 PMID: 24162567

29. Wu G, Day MJ, Mafura MT, Nunez-Garcia J, Fenner JJ, Sharma $M$, et al. Comparative analysis of ESBL-positive Escherichia coli isolates from animals and humans from the UK, The Netherlands and Germany. PLoS One. 2013;8(9):e75392.DOI: 10.1371/journal.pone.0075392 PMID: 24086522

30. Dutch Foundation of the Working Party on Antibiotic Policy (SWAB). NethMap 2015. Consumption of antimicrobial agents and antimicrobial resistance among medically important bacteria in The Netherlands in 2014. Bilthoven: RIVM. 2015. Available from: http://www.swab.nl/swab/cms3.nsf/ uploads/4F5AoD8E6FoDD139C1257E6E0051833A/\$FILE/ NethmapMaran2015\%20_webversie.pdf

31. Catry B, Cavaleri M, Baptiste K, Grave K, Grein K, Holm A, et al. Use of colistin-containing products within the European Union and European Economic Area (EU/EEA): development of resistance in animals and possible impact on human and animal health. Int J Antimicrob Agents. 2015;46(3):297-306. DOI: 10.1016/j.ijantimicag.2015.06.005 PMID: 26215780

\section{License and copyright}

This is an open-access article distributed under the terms of the Creative Commons Attribution (CC BY 4.0) Licence. You may share and adapt the material, but must give appropriate credit to the source, provide a link to the licence, and indicate if changes were made.

This article is copyright of the authors, 2016. 